\title{
Engaging in Collaboration
}

\section{Collaboration}

Collaboration is far from ubiquitous in the humanities, where the myth of the lone scholar is still a prevalent image. Collaboration has even been suggested as one of the practices dividing the Two Cultures, with the humanities as solitary scholarship and the sciences as teamwork. ${ }^{259}$ This division is reinforced by a reluctance of scholars to adopt collaboration in opposition to a "science model" of their research, with practices of collaboration standing in contrast to established disciplinary cultures. ${ }^{260}$ In this line, historical research has been said to require “'a single intellect to turn over the material'; 'ideas have to be shaped in the mind of the individual scholar.,"261

And yet, within the digital humanities, collaboration is emphasised. ${ }^{262}$ The different facets of digital history research and digital infrastructure development, such as computer technology, data management and historic inquiry, call for experts with different backgrounds to collaborate. In digital humanities collaborations, the most frequent reason for teamwork is the joining of different skill sets and expertise. ${ }^{263}$ Consequently, digital humanities and digital history are accompanied by a proliferation of project-based work and institutionalisation in centres and labs to sustain interdisciplinary collaboration. ${ }^{264}$ That is not

259 McCarty, Humanities Computing; Leslie A. Real, "Collaboration in the Sciences and the Humanities: A Comparative Phenomenology," Arts and Humanities in Higher Education 11, no. 3 (2012): 250-61, https://doi.org/10.1177/1474022212437310; Snow, The Two Cultures and the Scientific Revolution.

260 Jenny M. Lewis, Sandy Ross and Thomas Holden, "The How and Why of Academic Collaboration: Disciplinary Differences and Policy Implications," Higher Education 64, no. 5 (2012): 693-708, https://doi.org/10.1007/s10734-012-9521-8.

261 Tony Becher and Paul R. Trowler, Academic Tribes and Territories: Intellectual Enquire and the Culture of Disciplines, 2nd ed. (The Society for Research into Higher Education \& Open University Press, 2001), 126.

262 Borgman, “The Digital Future Is Now”; Klein, Interdisciplining Digital Humanities; Lisa Spiro, “'This Is Why We Fight': Defining the Values of the Digital Humanities,” in Debates in Digital Humanities, ed. Matthew K. Gold, online (University of Minnesota Press, 2012).

263 Lynne Siemens et al., "“More Minds Are Brought to Bear on a Problem': Methods of Interaction and Collaboration within Digital Humanities Research Teams," Digital Studies / Le Champ Numérique 2, no. 2 (2011).

264 Urszula Pawlicka-Deger, "The Laboratory Turn: Exploring Discourses, Landscapes, and Models of Humanities Labs,” Digital Humanities Quarterly 14, no. 3 (2020); Robinson, "Digital Humanities: Is Bigger, Better?”; Edin Tabak, “A Hybrid Model for Managing DH Projects,” Digital Humanities Quarterly 11, no. 1 (2017).

Ә Open Access. (C) 2021 Max Kemman, published by De Gruyter. (c) BY-NC-ND This work is licensed under the Creative Commons Attribution-NonCommercial-NoDerivatives 4.0 International License. 
to say that collaboration in the humanities mirrors the practices of the sciences. For example, one study of a digital humanities network found that the network provided the exchange of information and insights, without necessarily leading to co-authoring papers or co-analysing data. ${ }^{265}$ Within the network, scholars still mainly worked by themselves. Thus far, single-authored works remain the dominant form of authorship in the digital humanities. ${ }^{266}$

Collaborations in digital history can, therefore, be seen as a balancing of teamwork, such as jointly working towards the goal of a project, and individual scholarship. This balancing requires scholars to coordinate their goals and responsibilities with the team, so that the discrepancies between the ambitions of participants does not inhibit collaboration. ${ }^{267}$ Considering the uncertainties posed by digital history, goals emerge through continuous negotiation, rather than being fully established prior to collaborating. ${ }^{268}$ As such, collaborations require mutual trust to coordinate ill-defined goals. ${ }^{269}$ As collaboration is not already entrenched in their disciplinary culture, humanities scholars have to learn how to collaborate, and tend to do so by trial-and-error through continued interactions between team members. ${ }^{270}$

The current chapter explores how historians collaborate with one another and with cross-disciplinary partners. I thereby explore the dimension of engagement and consider how disciplinary and institutional boundaries are simultaneously crossed and established. By crossing the boundaries between disciplines, as interdisciplinary boundary crossing, the question is how this affects the relationship with a historian's disciplinary community. It has been argued that participants drift away from their disciplinary culture following the adoption of new

265 Anabel Quan-Haase, Juan Luis Suarez and David M. Brown, “Collaborating, Connecting, and Clustering in the Humanities: A Case Study of Networked Scholarship in an Interdisciplinary, Dispersed Team,” American Behavioral Scientist 59, no. 5 (2015): 565-81, https://doi.org/ $10.1177 / 0002764214556806$.

266 Julianne Nyhan and Oliver Duke-Williams, "Joint and Multi-Authored Publication Patterns in the Digital Humanities," Literary and Linguistic Computing 29, no. 3 (2014): 387-99, https://doi.org/10.1093/llc/fqu018.

267 Lynne Siemens, “'It's a Team If You Use "Reply All”': An Exploration of Research Teams in Digital Humanities Environments," Literary and Linguistic Computing 24, no. 2 (2009): 225-33, https://doi.org/10.1093/llc/fqp009.

268 Caroline Haythornthwaite et al., "Challenges for Research and Practice in Distributed, Interdisciplinary Collaboration," in New Infrastructures for Knowledge Production: Understanding e-Science, ed. Christine Hine (IGI Global, 2006), 143-66.

269 Petra Sonderegger, "Creating Shared Understanding in Research Across Distance: Distance Collaboration across Cultures in R\&D," in E-Research: Transformation in Scholarly Practice, ed. Nicolas W. Jankowski (Routledge, 2009).

270 Siemens et al., "More Minds Are Brought to Bear on a Problem." 
vocabularies and practices. ${ }^{271}$ If historians wish to discuss their digital research with other historians who are not a digital history collaboration, they may now find themselves confronted with a boundary of different practices and vocabularies that they did not experience before. As such, collaborations potentially constitute what I term intradisciplinary boundary construction.

In addition to such disciplinary boundary practices, digital history collaborations interact with institutional boundaries. Here too, institutional boundaries may be crossed, as scholars collaborate across different institutes, such as a collaboration between a history and a computer science department, or become embedded across different departments, e.g., a computer scientist employed at the history department. In contrast, digital history collaborations may lead to institutional boundaries to be constructed, as digital history centres or labs are institutionalised.

\section{Studying Engagement Across Boundaries}

In an earlier paper, I have explored these boundary practices quantitatively through an online questionnaire on digital humanities collaborations. ${ }^{272}$ I found that most participants in digital humanities collaborations came from the humanities and that most collaborations were led by humanities scholars. In line with these findings, two-thirds of the collaborations described by respondents were embedded in the humanities building of an institute, rather than a computer science building or a library. Finally, I found respondents communicated significantly more often with disciplinary peers outside their digital humanities collaboration than with crossdisciplinary collaborators.

These findings suggest that digital humanities collaborations are predominantly rooted within the humanities, corroborating the characterisation of "the digital humanities as a humanities project” by digital humanities scholar Patrik Svensson. ${ }^{273}$ Yet boundary practices can be subtle and are conducted over several years, aspects that are hard to investigate with an online questionnaire. How the dominance of humanities scholars in digital humanities collaborations shapes the trading zones in practice cannot be determined from the results of an online questionnaire. To deepen our understanding of boundary practices of digital history

271 Wenger, Communities of Practice, 103.

272 Max Kemman, “Boundary Practices of Digital Humanities Collaborations,” DH Benelux Journal 1 (2019).

273 Svensson, "The Digital Humanities as a Humanities Project." 
collaborations in practice, the next section, therefore, describes a qualitative study of digital history trading zones.

The below qualitative study describes several trading zones at one site, the University of Luxembourg. In 2013, the Institute for History at this university appointed a professor for contemporary and digital history, who became a driving force behind many subsequent developments of digital history at the university. As his first $\mathrm{PhD}$ candidate, hired in 2014, I had the opportunity to observe how he pushed for digital history and how collaborations were initiated, organised and conducted in practice. As such, I observed how he performed boundary practices with cross-disciplinary collaborators and disciplinary peers.

Four institutional units housed within the humanities building (Maison des Sciences Humaines) of the University of Luxembourg are central to this study:

1. the humanities faculty (Faculté des Sciences Humaines, des Sciences de l'Éducation et des Sciences Sociales - FHSE),

2. the Institute for History (IHIST, part of the humanities faculty established in 2003),

3. the Luxembourg Centre for Contemporary and Digital History $\left(C^{2} D H\right.$, established in 2016),

4. the Digital History Lab and the HiPoPhil Lab (both established in 2015) used by both the $\mathrm{C}^{2} \mathrm{DH}$ and IHIST.

This case study combined methods of ethnographic observation and oral history interviews. ${ }^{274}$ I collected observations on boundary practices as they are performed as well as reflections on how these practices were shaped over time. The below discussion thereby provides a diachronic perspective on engagement, boundary practices and how these change over time. I observed how the labs and centre were established, how historians participated and how conflicts were coordinated. To enrich my observations, I conducted 12 interviews with ten people. ${ }^{275}$ I interviewed eight historians on permanent contracts at the institute (five) and the centre (three). I furthermore interviewed two members of the centre's Digital Research Infrastructure unit, which provided technical support to the rest of the centre. By describing these institutional units by their histories, starting from the appointment of the professor for digital history, I aim to render visible the interventions and controversies that led to boundary constructions and boundary crossings.

274 Geertz, The Interpretation of Cultures; Donald Ritchie, Doing Oral History (Oxford University Press, 2014).

275 The interviews were semi-structured and diverged regularly from the questions. All interviews were recorded and manually transcribed and coded in MAXQDA. 
The following section describes the establishment of the $\mathrm{C}^{2} \mathrm{DH}$, especially focusing on the relations between the centre and the institute. For an overview of important events in the establishment of the $\mathrm{C}^{2} \mathrm{DH}$, see Figure 3 . In the section thereafter, I describe the establishment and evolution of the two laboratories and how historians from the centre and the institute engaged with the laboratories.

\section{Constructing Collaboration through a Digital History Centre}

Before describing the history of the $\mathrm{C}^{2} \mathrm{DH}$, it is of interest to briefly discuss what differentiates a "centre" from a "department". The literature on the proliferation of centres provides some insights into why the centre was established at the University of Luxembourg and how this affects the relationship with the institute.

In the history of academic research at universities, departments have become the authorities of disciplines where knowledge is generated and passed on to future generations of researchers. As the scholar of organisation studies Richard Whitley concluded; "[s]cience, therefore, became departmentalized”. ${ }^{276}$ In other words, disciplinary boundaries were very much the same as institutional boundaries. However, in several disciplines, this departmentalisation of science came under pressure as new problems required interdisciplinary approaches. This demanded new organisational forms, for which the interdisciplinary research centre is one model that has proliferated. ${ }^{277}$ Similar to the vision of interdisciplinary research working on real world problems, with results that can be applied in a societal context, these centres are envisioned to form a bridge between academia and society, both to industry and the public. ${ }^{278}$ In order to reach this vision, rather than an organisation into disciplines or around chairs of professors as seen in departments, centres tend to be organised according to research topics. This "'matrixing' of personnel” places researchers from different backgrounds around shared research topics. ${ }^{279}$ Through this reorganising of scholars, centres lead to increased

276 Richard Whitley, “The Rise and Decline of University Disciplines in the Sciences," in Problems in Interdisciplinary Studies, ed. R. Jurkovich and J.H.P. Paelinck (Gower Publishing Company, 1984), 16.

277 Paul K. Hoch, "New UK Interdisciplinary Research Centres: Reorganization for New Generic Technology,” Technology Analysis \& Strategic Management 2, no. 1 (1990): 39-48, https://doi. org/10.1080/09537329008523993; Robinson, “Digital Humanities: Is Bigger, Better?”

278 Gibbons, "Introduction”; Sally Wyatt, "Mode 2 in Action : Working Across Sectors to Create a Center for Humanities and Technology," Scholarly and Research Communication 6, no. 4 (2015).

279 Hoch, "New UK Interdisciplinary Research Centres," 40. 


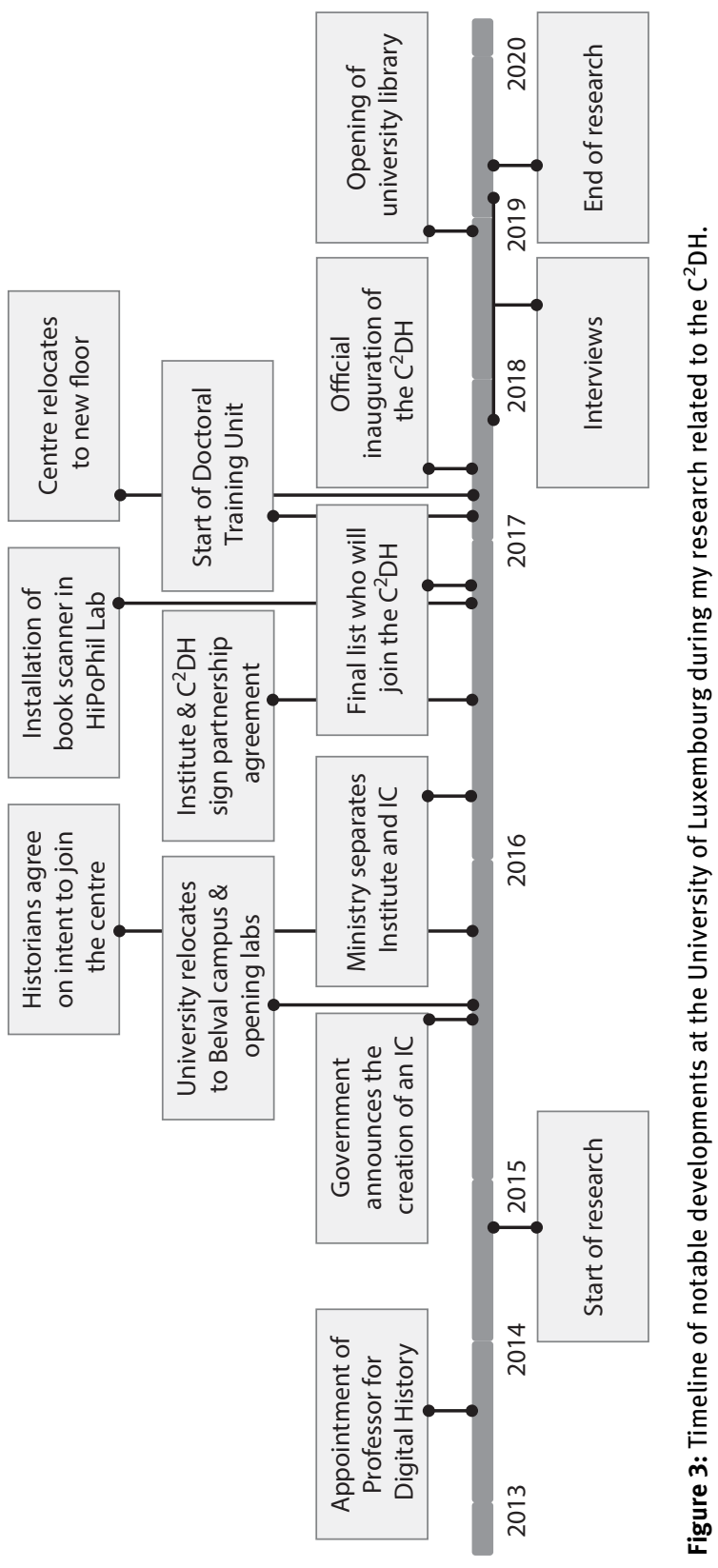


interdisciplinary collaboration both among members of the centre as with other institutes or corporations. $^{280}$

Centres thus reshaped the traditional organisational structure and cultural practices of research. ${ }^{281}$ The new organisational structure demanded new organisational styles in the form of managers. ${ }^{282}$ At least in the UK, centres adopted a discourse influenced by business and industry, in order to meet the expectations of societal and economic relevance. ${ }^{283}$ The proliferation and success of centres undermined the disciplinary authority of departments, especially with respect to research. ${ }^{284}$ The main struggle is, however, with respect to funding; whether the establishment of centres leads to renewed injections of research funding, or a redistribution leading to budget cuts for existing departments. ${ }^{285}$

Within the digital humanities as well, centres have a long history of providing the means to interdisciplinary collaborations among members as well as across institutional boundaries. ${ }^{286}$ As such, digital humanities centres have played an important part facilitating the growth of digital humanities as a field. More recently, however, digital humanities centres have been criticised for being an expensive model of scholarship, emphasising the need for continuous funding of work to sustain the organisation. It has consequently been argued that digital humanities centres have served their time as a model for digital humanities work. ${ }^{287}$

In summary, the literature shows not only that the organisation of scholars in a research centre rather than a department leads to different practices, but also

280 Branco L. Ponomariov and P. Craig Boardman, "Influencing Scientists' Collaboration and Productivity Patterns through New Institutions: University Research Centers and Scientific and Technical Human Capital,” Research Policy 39, no. 5 (2010): 613-24, https://doi.org/10.1016/j. respol.2010.02.013.

281 Julie Thompson Klein, “A Conceptual Vocabulary of Interdisciplinary Science,” in Practicing Interdisciplinarity, ed. Peter Weingart and Nico Stehr (University of Toronto Press, 2000), 3-24.

282 Hoch, "New UK Interdisciplinary Research Centres."

283 Greg Myers, "Centering: Proposals for an Interdisciplinary Research Center," Science, Technology, \& Human Values 18, no. 4 (1993): 433-59.

284 Whitley, "The Rise and Decline of University Disciplines in the Sciences."

285 Hoch, "New UK Interdisciplinary Research Centres."

286 Mila Oiva, "The Chili and Honey of Digital Humanities Research:The Facilitation of the Interdisciplinary Transfer of Knowledge in Digital Humanities Centers," Digital Humanities Quarterly 14, no. 3 (2020).

287 Andrew Prescott, "Beyond the Digital Humanities Center: The Administrative Landscapes of the Digital Humanities," in A New Companion to Digital Humanities, ed. Susan Schreibman, Ray Siemens and John Unsworth (John Wiley \& Sons, Ltd., 2015), 459-75, https://doi.org/10.1002/ 9781118680605.ch32; Robinson, “Digital Humanities: Is Bigger, Better?”; Mark Sample, “On the Death of the Digital Humanities Center,” @samplereality (blog), March 26, 2010. 
that the process of organising scholars into centres is highly political, especially in regard to issues of funding. In the following discussion, I show how this relates to the Luxembourg Centre for Contemporary and Digital History.

\section{Establishment of the $\mathrm{C}^{2} \mathrm{DH}$ : From Partners to Competitors}

One aspect that makes the academic landscape of Luxembourg rather unique is the close relationship between national politics and the university, since there is just one university in the country. The establishment of a centre for contemporary history too started not within the university, but as a political debate. A historian from the institute had been lobbying for a centre for contemporary history for a number of years. At that time, Luxembourg featured several organisations for historical research, namely the Institute for History at the university, but also independent from the university were centres such as the Centre d'Études et de Recherches Européennes Robert Schuman and the Centre Virtuel de la Connaissance sur l'Europe (CVCE), which both studied European integration and the European Union, the Centre de Documentation et de Recherche sur la Résistance, which studied the activities of the Luxembourgish resistance during World War II, and the Centre de Documentation et de Recherche sur l'Enrôlement forcé, which studied the Luxembourgish men who were forced to join the German army during World War II. This landscape of historical research institutes was upended following the national elections of 2013, which led to the formation of a new government. For a long time, the Christian CSV (Christian Social People's Party) had been the main party in government, but the 2013 elections led to a government consisting of the liberal DP (Democratic Party), the socialist LSAP (Luxembourg Socialist Workers' Party) and the Greens. The aforementioned historian who had been lobbying was affiliated with the LSAP, and this party subsequently started pushing for the establishment of a centre for contemporary history. This centre should then reinvigorate Luxembourgish contemporary history, as well as cut costs by combining the smaller independent centres into a single larger centre. ${ }^{288}$ A recent thesis from a $\mathrm{PhD}$ candidate of the Institute for History, who had shown that the Luxembourgish government during World War II was more accommodating to the Germans than was commonly believed, strengthened the argument that more research was needed into contemporary

288 Interviews 3 (December 2017), 5 (January 2018) and 7 (January 2018). 
Luxembourgish history. ${ }^{289}$ The proposal for a centre for contemporary history was then agreed upon and incorporated in the coalition agreement.

While the parties agreed there should be a centre, they disagreed about how to embed this centre in the existing academic landscape. According to my interviewees, the LSAP wanted to establish this as an independent research centre similar to other countries such as NIOD in the Netherlands or the Leibniz Centre for Contemporary History in Germany, but the DP wanted the centre within the university. ${ }^{290}$ At this point, historians from the institute started pushing for the centre to become part of the university, preferably part of the Institute for History. They feared that an independent centre could not guarantee sufficient academic freedom, and argued that the institute already did research on contemporary history, as exemplified by the $\mathrm{PhD}$ research on Luxembourgish collaborators in World War II. ${ }^{291}$ However, politicians feared that a centre as part of the Institute for History would not be visible enough and that contemporary historical research would end up being overshadowed by research on other historical periods.

The middle ground was to establish a centre within the university, but independent from the faculties. The University of Luxembourg already had an existing structure for this with the interdisciplinary centres (IC). At the time there were two ICs in biomedicine (LCSB - Luxembourg Centre for Systems Biomedicine) and ICT (SnT - Interdisciplinary Centre for Security, Reliability and Trust). These centres operated on the same level as faculties and the directors had the same status as deans. Thus, in June of 2015, the government officially announced the decision to establish an interdisciplinary centre for contemporary history and the university could start the search for a director of the centre to be. ${ }^{292}$ Afterwards, several historians were disappointed in the rector of the university. They said he should have pushed more for the centre to be integrated either in the Faculty of Humanities or the Institute for History, and that he too easily accepted the promised funding for a research centre. ${ }^{293}$

289 Vincent Artuso, "La Collaboration Au Luxembourg Durant La Seconde Guerre Mondiale (1940-1945): Accommodation, Adaptation, Assimilation”, Luxemburg-Studien = Études Luxembourgeoises, Band 4 (Frankfurt am Main: Peter Lang Edition, 2013).

290 Interviews 1 (November 2017) and 3.

291 Interviews 4 (January 2018) and 5.

292 "Déclaration du gouvernement sur la situation économique, sociale et financière du pays 2015 (traduction française)”, May 5, 2015, https://gouvernement.lu/fr/actualites/toutes_actua lites/discours/2015/05-mai/05-declaration-fr.html; "Résumé des travaux du 5 juin 2015”, June 5, 2015, https:/gouvernement.lu/fr/actualites/toutes_actualites/communiques/2015/06-juin/05conseil-gouvernement.html.

293 Interview 3. 
As mentioned above, the Institute for History had appointed a professor for contemporary and digital history in 2013. This professor decided to apply for the position of director and was indeed appointed. He was motivated by the rector and the dean of the Faculty of Humanities to do so. Yet some historians attempted to dissuade him from doing so; in one interview this was raised as a possible attempt to form a sort of "historical block" that would be ready to compete with the centre to be. ${ }^{294}$ While this strategy did not succeed, it exemplified the first signs of boundary construction.

Note that until now, there had only been plans for a centre for contemporary history. It was this professor for digital history who then pushed to make it a centre for contemporary and digital history. Of interest here is the parallel between argumentation for his initial appointment and his lobbying, which gives insight into the contingencies of how digital history came to be a topic of interest at the university.

In 2013, the professor for modern history was set to retire and a committee was established to hire a replacement. One of the historians from this committee, whom I interviewed, then argued that this was an opportunity to distinguish the history master from existing masters by bringing more attention to digital history. He argued that "there are hundreds of masters of European history, what could be a specific point to distinguish it from other masters is digital history."295 He pushed within the committee to hire a professor for modern and digital history, which they set out to do. They did not succeed in a candidate for modern and digital history, however, but did find a candidate for contemporary and digital history. At this point the committee had to decide what to give preference, either maintain the period and hire a professor for modern but not digital history or maintain the topic and hire a professor for digital but not modern history. To the disappointment of some historians, who had agreed to include the digital topic with the modern period, the committee decided to give preference to the digital topic and appointed a professor for contemporary and digital history. ${ }^{296}$ Later, with the formation of the centre, the professor for digital history followed the same line of argumentation. In the interview he said "there are ten [institutes for contemporary history], we should make a difference, we should be different, and that is why I think it should have 'digital' in the name.”297

The ministry exemplified an ambivalent relationship to this emphasis on digital history. On the one hand, early announcements, as well as the speech by the

294 Interview 4.

295 Interview 1.

296 Interview 1.

297 Interview 4. 
minister for higher education at the official inauguration of the centre in May 2017, spoke solely of the institute for contemporary history, l'Institute d'Histoire $d u$ Temps Présent, or the short-hand IHTP. Yet on the other hand, from the very first announcements, the ministry emphasised innovation of historical research. ${ }^{298}$ The centre's strategy was to be guided by digital history and linked to Digital Luxembourg, the government's initiative to coordinate the nation's digital strategy. ${ }^{299}$ Furthermore, the first large project of the centre would be an exhibition on World War I that was "not limited to a museum building. It is a digital, interactive and dynamic exhibition. This new project will thus be able to reach a wider audience". 300

Through arguments of differentiation with existing institutes, a professor of contemporary and digital history who did not meet the original requirement of modern history was appointed and a centre planned for contemporary history became concerned with digital history. Both aspects show that involved historians and politicians shared an understanding of the potential for digital history in Luxembourg, with politicians arguing that "the aim is to seize the opportunity to create a new innovative centre by occupying a niche of competence with socio-economic potential for the Grand Duchy." ${ }^{301}$ As a result, the University of Luxembourg founded one of the largest centres related to digital history in the world, consisting of over 100 researchers and support staff. ${ }^{302}$

With the decision to embed the centre inside the university, another debate was how to fit the centre in the existing organisational structure. During the planning phase, historians of the institute conceived of several models for interaction between the institute, the faculty, and the centre. One model was to work with dual affiliations, with the historians in the institute, but affiliated to the centre for interdisciplinary projects. Another model was to define the centre as a digital humanities service centre that would provide expertise and support to the rest of the Faculty of Humanities, as a more auxiliary science. ${ }^{303}$ Yet another model was to define four research topics for the centre: digital history, contemporary Luxembourgish history, contemporary European history and longue duree. The

298 "Résumé des travaux du 5 juin 2015".

299 “About Us”, Digital Luxembourg website, accessed February 15, 2021, https://digitalluxembourg.public.lu/about-us.

300 "Déclaration du gouvernement sur la situation économique, sociale et financière du pays 2015 (traduction française)", quote translated from French. The project itself can be found at "Éischte Weltkrich", accessed May 12, 2021, https://ww1.lu.

301 "Résumé des travaux du 5 juin 2015", quote translated from French.

302 "Self-Evaluation Report", Luxembourg Centre for Contemporary and Digital History, April 2019.

303 Interviews 2 (December 2017), 3 and 7. 
longue dureé topic would then consist of the pre-contemporary historians from classical, medieval and modern history. ${ }^{304}$ This model was favoured by the historians and at an institute meeting near the end of 2015, the historians voted they would all join the centre to be. ${ }^{305}$

Yet this vote was overruled when the ministry decided this was not the model they favoured. The minister for higher education explicitly told the director of the centre that the professors for classical history and medieval history would not be allowed to join the centre. Boundary construction was performed by a third party, in that the ministry decided the contemporary and non-contemporary historians would not be part of the same institutional unit. In the interviews, historians speculated about the reasoning for this political decision, which significantly affected later relationships between historians. The main reason seemed to be related to why the centre could not be part of the Faculty of Humanities or Institute for History in the first place, namely that the ministry feared non-contemporary historians would overshadow contemporary historians in the centre. A more political reason that was speculated was that these two professors from classical and medieval history were supposedly associated with the CSV, the Christian party that led government before the new government. As written by one historian in an opinion piece in a Luxembourgish newspaper: "the $\mathrm{C}^{2} \mathrm{DH}$ is seen as the consecration of a certain progressive spirit against an Institute for History associated with a Catholic movement, necessarily conservative, even nationalist." ${ }^{306}$ Consequently, the final model was to have two separate institutional units. The Institute for History was to remain within the Humanities faculty, while the centre would become an IC.

The centre organised itself around four research topics; Public History, Contemporary History of Luxembourg, Contemporary History of Europe and Digital History and Historiography. Furthermore, a separate unit for Digital Research Infrastructure was established to facilitate the technical necessities of the four research topics. The centre furthermore employed support staff such as secretaries, financial administrators and communication officers. Apart from the two professors of classical and medieval history, other historians were given the choice to join the centre or remain in the institute. Among these historians, some chose to join the centre as they felt their research was mainly about contemporary history.

304 “IC LICHT_profile_proposal_InstitHIST”, Institute for History, University of Luxembourg, October 2015.

305 “Protokoll Des Mercredi de l'histoire Vom 14. Oktober 2015”, Institute for History, University of Luxembourg, October 20, 2015.

306 “Quelle Dette Pour Quelle Université?”, D’Lëtzebuerger Land, July 14, 2017, https://web.ar chive.org/web/20190114192601/http://www.land.lu/page/article/148/333148/FRE/index.html, quote translated from French. 
They considered they could improve their research in a setting more focused on contemporary history. Those who chose to remain in the institute did so because they felt that their main research was not about contemporary history, and in some cases because they wanted to remain loyal to the institute. Notice that the reasons were thus not related to digital history. Of the then 34 members of the institute, 14 moved to the centre, including myself. ${ }^{307}$

Having had a choice, this did not mean these scholars felt empowered. Some were disappointed that the ministry reached inside the university, affecting academic freedom. Others were mainly disappointed that two years of debates among themselves for appropriate models were simply overruled, and that they lacked any power to shape the centre. Consequently, some historians from the institute became very critical about the centre's existence, reinforcing the boundaries constructed by the ministry. These criticisms were then reiterated in discussions around where chairs should be embedded. When a professor from the Institute for History retired in 2017, both the centre and institute had the ambition of appointing a successor. As a new centre, with the ambition of becoming a centre of excellence, the rector promised the chair would be succeeded within the centre. In opposition, the institute desired to maintain its research agenda, and the dean of the Faculty of Humanities promised the chair would be succeeded within the institute. Moreover, I described above how the previous professor of modern history came to be replaced by a professor of contemporary history, who then became director of the centre. Historians from the institute consequently argued that his chair should be returned to the institute, as it was originally the chair of modern history. ${ }^{308}$

However, the first position was funded by government during the establishment of the university in 2003 to attract Luxembourgish secondary school teachers to create a critical mass of scholars at the university. The minister of higher education suggested that if a successor was to be appointed, this successor would again be a secondary school teacher, a suggestion heavily critiqued. ${ }^{309}$ Yet he did not offer concrete plans for the appointment of a successor. For the second position, the institute was dependent of the rectorate, which was going through a financial crisis and significantly cut research budgets. ${ }^{310}$ These struggles thus reached a stalemate without any concrete plans for the future from the ministry or rectorate. This episode demonstrated that while some scholars saw this as a struggle between

307 Membres_InstitutHIST_October 2016, November 10, 2016.

308 Interview 1.

309 "Quelle Dette Pour Quelle Université?”

310 "Le C2DH, Victime Collatérale de La Crise à l'Uni”, Paperjam, July 7, 2017, https://web.ar chive.org/web/20170708123454/http://paperjam.lu/news/le-c2dh-victime-collaterale-de-la-crise-aluni. 
the centre and the institute, this was caused or at least significantly influenced by a top-down political decision of funding, with historians from neither unit really in power to push for a decision.

\section{Situating the Centre: Interacting through Open Doors}

The next phase of boundary practices started when the centre became physically real in office space. Since the University of Luxembourg moved to a new campus in the summer of 2015, all historians all been located on the second floor of the Maison des Sciences Humaines, the building accommodating the Faculty of Humanities. In April 2017 the historians who had joined the centre moved to the fourth floor of the same building. ${ }^{311}$ The next month, on May 22, 2017, the official inauguration of the centre took place. ${ }^{312}$ On this floor, the centre was accommodated in its own wing of the building, which had been empty so far. The constructed boundaries of who was part of the centre and who not thereby became a physical distance as the centre moved to a different floor. Interviewees were divided over whether this increased physical distance led to more positive boundary practices. In general, interviewees corroborated the literature described earlier; with the increased physical distance, it became harder to coordinate, there were fewer informal meetings, a lack of joint coffee breaks and consequently fewer boundary crossings between the institute and the centre. ${ }^{313}$ The historians from the centre added this was especially to the regret of historians from the institute, who supposedly felt left behind, having lost many of their colleagues.

The historians from the institute agreed that there was the danger of being seen as the "leftovers", but one interviewee from the institute argued that the increased physical distance improved relations. While "out of sight is out of mind" might in primary instance make collaboration more difficult, this interviewee said it was also healthy not to be continuously confronted with the centre. With the centre's historians gone, the institute could now re-energise the connections among themselves to identify and build a new identity. ${ }^{314}$ Just like the centre had, the institute developed a profile based on research topics related to spaces,

311 C2DH Move - April 14, 2017, March 16, 2017.

312 Inauguration officielle du Luxembourg Centre for Contemporary and Digital History, May 23, 2017, https://www.c2dh.uni.lu/news/inauguration-officielle-du-luxembourg-centrecontemporary-and-digital-history.

313 Interviews 1, 2, 3, 4, 5 and 7.

314 Interview 2. 
material, national identities and power. ${ }^{315}$ This could be interpreted as a form of boundary construction, boundary work to shape the institute. Yet this boundary construction would hopefully lead to improved collaborative boundary crossing in the future as the two institutional units would stand on a more equal footing, both with strong identities and ambitions, rather than a power relation between a progressive centre and an institute left behind.

For the centre, the move to a new physical space offered the opportunity to embed its ideals in the architecture. The director envisioned a transparent organisation, defined not by hierarchies but by collaboration. These visions were interpreted architecturally by installing glass corridor walls, several meeting rooms and a large open office for the approximately $20 \mathrm{PhD}$ candidates, including me (see Figure 4). Others in the centre shared an office with one or two others and adopted an "open door policy"; doors were always open for joint discussions and collaboration. This was in contrast to the offices on the second floor, where doors had small windows that most scholars had covered with a poster and $\mathrm{PhD}$ candidates shared offices with one or two others.

Over time this architecture became understood not only as a way to showcase ambitions for collaboration, but actually a reflection of individual intentions to collaboration. This caught my attention when some of the $\mathrm{PhD}$ candidates criticised

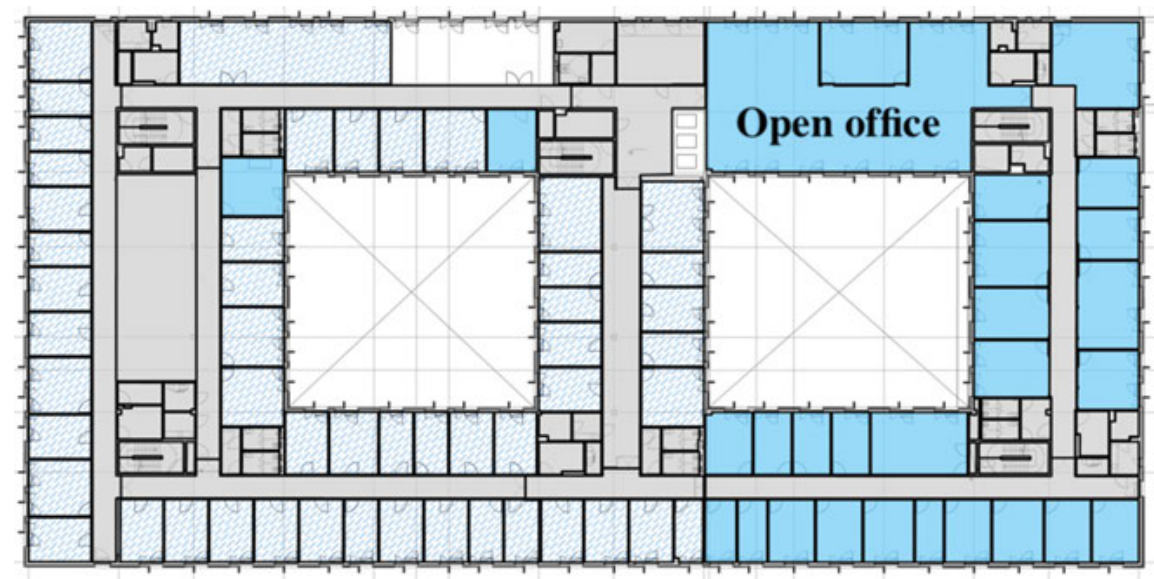

Figure 4: Floorplan of the fourth floor in the Maison des Science Humaine, University of Luxembourg. In blue the area assigned to the $\mathrm{C}^{2} \mathrm{DH}$. Exported October 2018.

315 “Research", accessed February 17, 2021, https://history.uni.lu/. 
the working conditions in the open office space. Some felt they could not concentrate in a space with 20 others, lacked privacy, or were disturbed by additional noise from the hallway due to the open doors. Several $\mathrm{PhD}$ candidates entered a process of negotiation with the management of the centre in order to decrease disturbances and improve privacy, for example by closing the doors. However, of interest is that these complaints were simultaneously criticised as conflicting with the collaborative spirit of the centre. The negotiations, therefore, aimed to negotiate the balance between individual working conditions and the collective collaborative spirit. Tim van der Heijden and Andreas Fickers in their analysis of the open office conclude that, ultimately, collaboration did not take place within the open office, but in other spaces within the building. ${ }^{316}$ However, they show that the open office facilitated the initiating of collaborations, making it easy to approach potential collaborators before moving to other spaces for further collaboration without disturbing others.

This episode demonstrated the bidirectional relation between physical distance and boundary practices. Maintaining a short physical distance led to boundary crossing, while preferring increased physical distance was interpreted as boundary construction. Subsequent negotiations did not just aim to maintain boundary crossing within the centre, but emphasised the need to shorten the physical distance, and to remove physical barriers such as closed doors.

Maintaining a short physical distance furthermore facilitated cross-disciplinary boundary crossing within the centre. The Digital Research Infrastructure (DRI) unit supported the historical research activities of the centre, consisting of experts coming from engineering, software development, computational linguistics, design and archives. The DRI was arguably positioned between regular IT support and research, providing support for a wide variety of tasks including advanced functionalities in Excel, setting up and maintaining websites, and handling research software licenses. ${ }^{317}$ The open door policy of the centre was a significant aspect of the DRI, allowing low-threshold face-to-face communication to coordinate what needed to be provided, and helping historians on their way to work independently afterwards. More towards active research, the DRI investigated how to provide a common digital infrastructure for historical data management. This infrastructure would consist of a graph database including people, organisations, places and time, with heterogeneous semantic relationships. The argument was that these were fundamental units of historical research, allowing a wide range

316 Andreas Fickers and Tim van der Heijden, "Inside the Trading Zone: Thinkering in a Digital History Lab,” Digital Humanities Quarterly 14, no. 3 (2020).

317 Interview 9 (January 2019). 
of historical research projects to be supported. ${ }^{318}$ Especially for research related to Luxembourg, the ambition was that eventually certain entities such as politicians or organisations might be relevant across multiple research projects, providing cross-project connections. Yet a significant decision by the DRI was to provide individually tailored infrastructures. The DRI aimed to provide combinations of technologies to fit historians' projects, rather than a common generic technology and shaping historians to fit in the provided workflow.

"Infrastructure" was thereby interpreted as providing access to a wide array of infrastructural components that could be fitted by the DRI to fit a historian's project. Historians were not pushed to adopt digital history methodologies. The boundary practices between the centre and institute following the political and physical interventions were, therefore, not reiterated by some digital methodological intervention.

While boundary construction occurred, leading to "us" versus "them" attitudes and interviewees admitted that relations were tense right after the split, they also emphasised this was the past and that they saw opportunities for collaboration. During the summer of 2016 already, the director of the $\mathrm{C}^{2} \mathrm{DH}$ and the head of the Institute signed an agreement of privileged partnership, formalising their intention to collaborate from the recognition of complementary research agendas and need to share resources. ${ }^{319}$ Despite the interventions, several interviewees agreed that the split between the centre and the institute was not an accurate representation of how historians are organised and work. ${ }^{320}$ Not all historians from the centre were confident that their research methods would fall within the scope of digital history. Historians from the institute emphasised that they too conducted contemporary and digital history. The opportunity that arose out of this ambiguity was the possibility of boundary crossing. Especially historians who had been at the university before the split were positive that future collaborations would prove fruitful. Historians that joined the university after the split had more difficulty imagining collaboration, mainly due to a lack of awareness of who could be a partner from the other unit. ${ }^{321}$

318 Interview 9.

319 Partnership Agreement between the Institute for History (University of Luxembourg, Faculty of Language and Literature, Humanities, Arts and Education) and the Center for Contemporary and Digital History (University of Luxembourg), 2016.

320 Interviews 2, 4, 5, 6 (January 2018) and 7.

321 Interview 6. 


\section{Collaborating Units of Historians}

Yet, rather than research projects, the most important collaboration was in education. The centre and the institute jointly organised the history bachelor and master and taught courses together. With respect to teaching, both units were satisfied that the increased funding towards the centre meant there were more historians who could teach. Already before the split, the history master included mandatory courses related to digital history, and both the bachelor and master included courses related to all historical periods. One interviewee argued that "with respect to everything regarding education we are simply one group of historians, it is only at the level of research where you have this split." ${ }^{322}$ Historians from both units described how they used digital means in their teaching and challenged students to use digital tools for their research papers. There was, however, also some anxiousness about this collaboration. One interviewee from the centre said that historians from the institute were afraid that the centre would make the master completely digital. ${ }^{323}$ This fear was not repeated in the interviews with historians from the institute, but one of these historians did express fear that students were drawn more towards contemporary history than earlier periods. He noticed that more master theses were supervised by historians from the centre and covered contemporary history. ${ }^{324}$

The units also collaborated in the training of PhD candidates. In 2015 the Luxembourg National Research Fund (Fonds National de La Recherche, FNR) introduced PRIDE (Programme for Research-Intensive Doctoral Education) to fund groups of PhDs rather than individual positions. ${ }^{325}$ Professors were forced to jointly request funding. The director of the centre, then still at the institute, was the PI of an application for a doctoral training unit in digital history and hermeneutics, which led to $13 \mathrm{PhD}$ positions and one post-doc who started from March 2017. ${ }^{326}$ This grant was a collaboration between the centre, the Institute for History, as well as the institutes for philosophy, linguistics, psychology, geography and computer science. This group of PhDs also acted as boundary crossing; while embedded in the centre (in the aforementioned open office space), they were affiliated to both the centre and the institutes of their supervisors. Explicitly

322 Interview 4.

323 Interview 1.

324 Interview 3.

325 “Programme summary”, accessed February 17, 2021, https://www.fnr.lu/fundinginstruments/pride/.

326 ““'Digital History and Hermeneutics” Doctoral Training Unit”, accessed May 12, 2021, https:// dhh.uni.lu/about-us/. 
envisioned as a trading zone of digital history, the idea was to have all the $\mathrm{PhD}$ candidates in one space for interdisciplinary collaborations. ${ }^{327}$ From the start, however, the PI had to ensure this actually happened. PhD candidates were given desks at their respective institutes, close to their supervisors. There was thus a competition for physical distance to the $\mathrm{PhD}$ candidates. The double affiliations meant $\mathrm{PhD}$ candidates were expected to join in on meetings, social events and training of both the centre and their affiliated institutes. Some $\mathrm{PhD}$ candidates consequently became confused about which institute they primarily belonged to and supervisors competed for primary affiliation. Over time, these frictions were decreased through discussion, coordination and individual preferences of $\mathrm{PhD}$ candidates.

Both aspects of collaboration, training students and PhD candidates, demonstrate how boundary crossing and boundary construction are entwined. The trading zone scheme succeeded insofar as it led to cross-disciplinary collaborations of $\mathrm{PhD}$ candidates that co-authored papers. However, a problem was the balance in pursuing a collective cross-disciplinary doctoral programme, while PhD candidates were eventually evaluated on individual disciplinary work. ${ }^{328}$ On a small scale, the $\mathrm{PhD}$ candidates in a single office thereby exemplified the potential and friction of digital history trading zones.

In conclusion, the $\mathrm{C}^{2} \mathrm{DH}$ became an interdisciplinary research centre similar to descriptions in the literature. The centre was organised in research teams around topics rather than chairs. These teams met on a regular basis, each headed by a research manager that was also part of the management committee of the centre. Within the centre, English became the working language, in order to sustain an international outlook. This stood in contrast with German and French as working languages in the institute which sustained relationships with German and French academic communities. ${ }^{329}$ The centre was established in order to bridge the academic historical work to society and was actively evaluated on societal impact. To meet this requirement, the centre professionalised communication and outreach by installing a communication office, an editorial board for the website that urged all members to write blog posts about events, conferences and research, and by organising regular public events such as debates, lectures, or project presentations. From this, one can see how the centre is an example of the reshaping of organisational structure and cultural practice of research. ${ }^{330}$ The centre also became

327 "PRIDE Application Form - Digital History and Hermeneutics", 2015.

328 "PRIDE Periodic Report DTU-DHH (Digital History \& Hermeneutics)”, 2018.

329 On a personal note, this switch to English enabled my integration within the centre to a greater extent than had been the case within the institute, due to my proficiency of these languages.

330 Klein, “A Conceptual Vocabulary of Interdisciplinary Science.” 
the subject of controversies around funding, leading both to a new injection of funding for the university, as well as a redistribution as scholars moved between the institute and the centre. ${ }^{331}$

\section{Shifting Associations of the Digital History Lab}

While centres have proven a successful model to facilitate interdisciplinary collaboration among scholars, another model has been the laboratory. While history professionalised through institutionalisation in departments, other disciplines such as chemistry and physics institutionalised in laboratories, where labs became "badges of scientific credibility and productive utility." 332 Labs did so by association to several concepts that became central to science.

According to the sociologist of science Bruno Latour, the lab as a space is simply a mundane room. ${ }^{333}$ What defines the lab is that it allows to investigate phenomena through trial-and-error, where every trial is thoroughly documented. As such, the lab is associated with experimentation. The sociologist of science Karin Knorr Cetina described the lab as a space where "nature" is excluded, kept outside of the lab. ${ }^{334}$ She later elaborated this by describing the lab according to three features. First, objects are not taken in whole, but only specific features of interest are considered. Second, objects are not taken in their original location, but incorporated in the laboratory setting. Third, objects are not taken when they naturally occur, but their occurrence is created. ${ }^{335}$ As such, the lab is associated with controlled settings.

The diversity of tasks means labs tend to employ a range of personnel such as PhDs, postdocs and lab technicians. ${ }^{336}$ The lab is thereby associated with collaboration. Labs provide a safe environment, equipment and services required

331 Hoch, "New UK Interdisciplinary Research Centres.”

332 Catherine M. Jackson, "Chemistry as the Defining Science: Discipline and Training in Nineteenth-Century Chemical Laboratories,” Endeavour 35, no. 2-3 (2011): 61, https://doi.org/ 10.1016/j.endeavour.2011.05.003.

333 Bruno Latour, “Give Me a Laboratory and I Will Raise the World," in Science Observed, ed. Karin Knorr Cetina and Michael Mulkay (SAGE Publications, 1983), 141-70.

334 Karin Knorr Cetina, "The Ethnographic Study of a Scientific Work: Towards a Constructivist Interpretation of Science," in Science Observed: Perspectives on the Social Study of Science, ed. Karin Knorr Cetina and Michael Mulkay (SAGE Publications, 1983), 115-40.

335 Karin Knorr Cetina, "The Couch, the Cathedral, and the Laboratory : On the Relationship between Experiment and Laboratory in Science," Science as Practice and Culture (1992), 117. 336 Knorr Cetina, Epistemic Cultures; Latour and Woolgar, Laboratory Life, 197. 
to conduct research and provide training. ${ }^{337}$ As such, the lab should always be associated with infrastructural space, despite debates on where a lab is located or what activities are performed in a lab. ${ }^{338}$ Finally, with the institutionalisation of disciplines in laboratories, the work in labs is what provides the means for the scientific enterprise of hypothesis testing, discovery and falsification. The lab is therefore associated with knowledge production. ${ }^{339}$

Traditionally associated with sciences such as chemistry, physics and biology, the laboratory terminology is regularly imported into the humanities, usually in reference to one or a combination of the features introduced above. For example, libraries have been called the laboratories for the humanities, in order to reference libraries as sites of knowledge production. ${ }^{340}$ In contrast, archives have been argued to be more similar to fieldwork rather than labs, where research depends on local conditions, rather than the association of controlled settings. ${ }^{341}$ In the context of digital methods, the computer has been called a lab, providing an environment to run tests. ${ }^{342}$ Announcing the launch of King's Digital Lab, its director James Smithies wrote of digital tools as similar to laboratory equipment to run experiments. ${ }^{343}$ Thus, the computer incorporates the lab's association of experimentation. However, the digital humanities scholar Urszula Pawlicka-Deger argues the humanities lab is essentially a tactical term, in order to incorporate the aforementioned scientific credibility and productive utility of the sciences. ${ }^{344}$ In a later article, she furthermore notes that this usage of the laboratory is proving increasingly successful as an alternative to the centre. ${ }^{345}$ It is, therefore, of interest that the University of Luxembourg initiated both a centre as

337 Jackson, "Chemistry as the Defining Science.”

338 Graeme Gooday, "Placing or Replacing the Laboratory in the History of Science?," Isis 99, no. 4 (2008): 783-95, https://doi.org/10.1086/595772; Catherine M. Jackson, “The Laboratory,” in A Companion to the History of Science, ed. Bernard Lightman (Wiley-Blackwell, 2016), 296-309.

339 Jackson, "The Laboratory."

340 Job Cohen et al., Duurzame Geesteswetenschappen: Rapport van de Commissie National Plan Toekomst Geesteswetenschappen (Amsterdam University Press, 2008); Sue Stone, "Humanities Scholars: Information Needs And Uses,” Journal of Documentation 38, no. 4 (1982): 292-313, https://doi.org/10.1108/eb026734.

341 Eskildsen, "Leopold Ranke's Archival Turn: Location and Evidence in Modern Historiography." 342 Piet Hut and Gerald Jay Sussman, "Advanced Computing for Science," Scientific American 257, no. 4 (1987): 136-45; cited in Knorr Cetina, Epistemic Cultures.

343 James Smithies, “KDL, Established 2016,” King’s Digital Lab blog, 21 October, 2016, https://www.kdl.kcl.ac.uk/blog/kdl-launch/.

344 Urszula Pawlicka, "Data, Collaboration, Laboratory: Bringing Concepts from Science into Humanities Practice,” English Studies 98, no. 5 (July 4, 2017): 526-41, https://doi.org/10.1080/ 0013838X.2017.1332022.

345 Pawlicka-Deger, "The Laboratory Turn." 
well as a lab for digital history, which allows us to explore how these different models are constructed by historians.

Below, I describe the history of two humanities labs at the University of Luxembourg. Through this history, I show how the associations of the labs to the concepts above were not stable but were instead constantly negotiated and shifted.

\section{The HiPoPhil Lab and Digital History Lab: Shifting Associations}

As mentioned in the previous section, the University of Luxembourg moved to a new campus in the summer of 2015. In the newly built Maison des Sciences $\mathrm{Hu}$ maines a floor was envisioned for laboratories for the disciplines accommodated in this building. At the previous site, where the historians had been since 2003, the historians had a seminar room with their books and a manual book scanner so that they could lecture students in their own historical library, amid the sources. The historians set out to replicate this seminar room in the new humanities building on the laboratory floor. However, they had to find ways to argue that they too needed a lab. The new campus would get a university library building at the end of $2018 .^{346}$ Several interviewees noted that the historians were consequently not allowed to maintain a space for their own library. ${ }^{347}$ However, an alternative space to store the books between 2015-2018 was not offered either. The developers furthermore associated labs with experimentation and assumed that historians did not need a lab.

Yet the historians desired to claim space on the laboratory floor to store their books. They followed two strategies to this end. First, to strengthen their position, they made a joint proposal for a lab for historians, but also for philosophers and political scientists, leading to the name HiPoPhil Lab (History, Political science, Philosophy). Second, they had to argue how their use of the room would fall within the scope of a "lab". This is a very literal example of "lab" as a tactical term, while also demonstrating a coercive push towards scientific associations: the historians were not allowed to create their own library, so they associated their library with the concepts of a lab. ${ }^{348}$ They did so by emphasising practices of digitisation and creation of databases, requiring scanners and computers with

346 “This Is the Day!”, Luxembourg Learning Centre, December 9, 2018, https://llc.uni.lu/en/ 2018/09/12/this-is-the-day/.

347 Interviews 2 and 7.

348 Pawlicka, "Data, Collaboration, Laboratory: Bringing Concepts from Science into Humanities Practice.” 
specialised software. They also wrote about "sources" rather than "books" to steer clear of further associations of it being a library. ${ }^{349}$ They thereby associated the lab with infrastructural space as the site of knowledge production.

The founding of the Digital History Lab is less clear. Most interviewees assumed that the professor for digital history came up with the idea and had lobbied for it. However, this professor said that the lab was already part of the job description, made possible by the hiring committee. In turn, a historian who was part of this committee said that the lab was actually made possible by the historian who had also led the arguments for the HiPoPhil Lab described above. Finally, this historian again said that to his knowledge, the professor for digital history came up with the idea for this lab. ${ }^{350}$ Be as it may, the professor for digital history was excited to cultivate this lab. He did not take "lab" to be a tactical term, but envisioned more hands-on practices of history, in association with experimentation, and students working in groups, in association with collaboration. In 2014, this professor and I set out to design the technical specifications of the lab, following these two associations. We first thought of the lab as a computer lab, to provide computational power for digital methods. We then became aware that opposite the lab would be a TIC lab (Technologies de l'Information et de la Communication), basically a room filled with computers. We then limited the scope of PCs to just a few for more specialised tasks. Our alternative idea was to explore the lab as a 3D lab, with 3D scanners and a 3D printer, for historians to experiment with the tacit experience of historical objects and their 3D copies. The two labs, sharing a door between them, became more entwined after the opening in 2015. Two 3D scanners were made available in the Digital History Lab and a full-colour 3D printer was set up in a small additional room opposite the HiPoPhil lab. For an overview of the laboratory floor, see Figure 5.

However, despite offering the means for associations to experimentation and collaboration, these were hardly appropriated by historians from either the institute or the centre. In the end, the political scientists and philosophers hardly used the lab. The HiPoPhil Lab was too small for lectures as it could not fit enough students, so it was not used for classes. Finally, the manual book scanner that had been present in the old seminar room was placed in the lab, but the historians and technical support of the university were unable to get it to work after the move. Thus, most historians ultimately used it as a library rather than a lab, mainly associated to infrastructural space. Still, the argument had succeeded in getting the space.

349 “Form Template_HiPoPhil_2014_EN”, 2014.

350 Interviews 1, 3, 4, 5 and 7. 


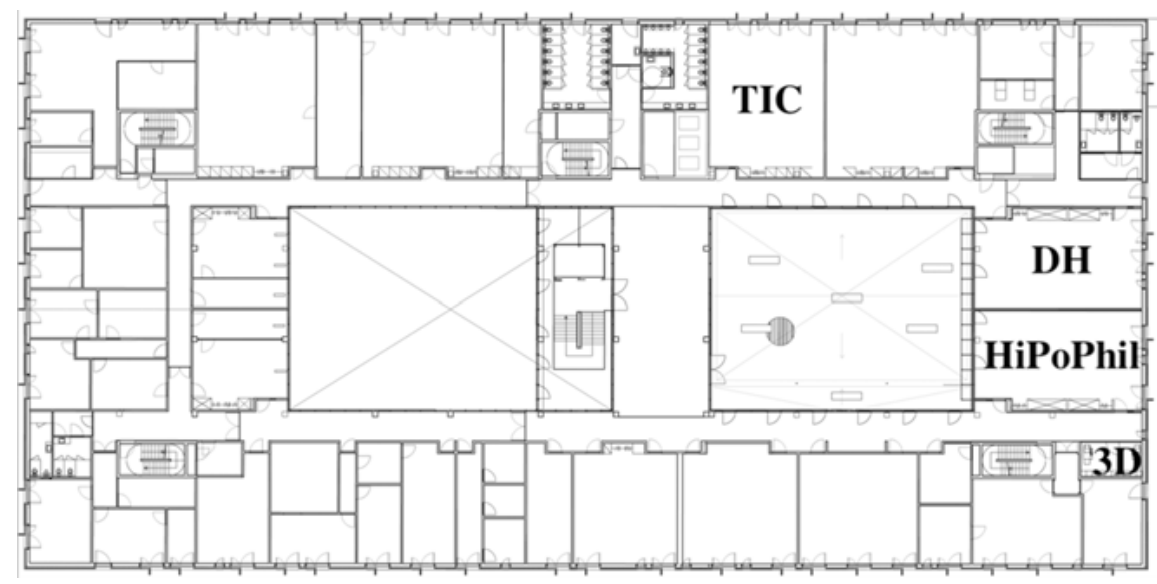

Figure 5: Floorplan of the first floor in the Maison des Science Humaine, University of Luxembourg. The labs described in the text are labelled. Exported October 2018.

The Digital History Lab too became increasingly associated with infrastructural space, set up around a big screen for presentations. It became used for lectures and examinations. Some historians shifted to a tactical usage of the term "lab", with the Digital History Lab simply being closer to their offices than other lecture rooms. ${ }^{351}$ With respect to research, the labs became strongly associated with infrastructural space to provide equipment and services related to digitisation. An automated book scanner was installed in the HiPoPhil Lab, with which books could be automatically digitised, processed using optical character recognition (OCR) and stored in a virtual library. The scanner, OCR software and virtual library were maintained by the centre's Digital Research Infrastructure unit. The physical infrastructure of the labs thereby became entwined with the digital infrastructure of the centre. Following requests from historians, more equipment for digitisation was installed for photos, negatives, maps and other sources. Yet a difference between the digital infrastructure of the DRI unit and the physical infrastructures of the labs was in the consequences of acquiring new technology. In contrast with software licences, the acquisition of equipment requires training to be scheduled, space to be reserved to place the equipment and expertise for maintenance. ${ }^{352}$ As such, the physicality of lab equipment carried "material implications" that shaped subsequent 
opportunities. ${ }^{353}$ That is, to use equipment optimally requires shaping research to include existing equipment, otherwise equipment ends up unused.

The first year, I maintained the lab to a large extent together with IT support from the university, creating inventories of necessary equipment and learning how to use them. At the end of 2016, a full-time coordinator was hired by the $\mathrm{C}^{2} \mathrm{DH}$ to maintain equipment and provide support for both the labs. The book scanner was a rather expensive machine that could be damaged easily through mistakes, e.g., it contained glass surfaces that would scratch if a user was wearing metal rings or wristbands. The coordinator therefore took it upon himself to operate the machine. The open door policy of the centre was hence not imported to the labs, which required control over access to ensure equipment and the rooms themselves stayed in order. ${ }^{354}$ Digitisation of books consequently became an informal service provided through the coordinator and book scanner. Historians could leave a stack of books with a note on his desk, and after two or three weeks they would receive an email with the digitised book files and the stack of books returned on their own desks. Does this make the coordinator similar to a lab technician described in the study of Bruno Latour and Steve Woolgar, thereby importing the association of collaboration? ${ }^{355}$ Contrary to those lab technicians, the artefacts handled by the lab coordinator were not used within the lab. That is, historians read books outside of the lab, imported the books into the lab for digitisation, but the digital files were then exported out of the lab for use by historians. The act of digitisation alone was not part of the research. The lab was then arguably not the site of knowledge production. In these cases, which were the majority of digitisation requests, the activities of the lab were arguably insufficient to be associated with collaboration as part of research. The coordinator in this situation was working for rather than with historians, while collaboration should entail a more equal ground of engagement. ${ }^{356}$

The informal process and hidden labour of leaving books with a note on the coordinator's desk had two consequences. First, many historians did not become aware of the time investment going into digitisation. The stack of books and sources to be digitised soon became an almost full-time task, leading to hiring of multiple student workers to support the operation of the automated book

353 Anna Foka et al., "Beyond Humanities qua Digital: Spatial and Material Development for Digital Research Infrastructures in HumlabX,” Digital Scholarship in the Humanities 33, no. 2 (June 1, 2018): 264-78, https://doi.org/10.1093/llc/fqx008.

354 Interview 8.

355 Latour and Woolgar, Laboratory Life.

356 Willard McCarty, "Collaborative Research in the Digital Humanities," in Collaborative Research in the Digital Humanities, ed. Marilyn Deegan and Willard McCarty (Ashgate, 2012), 1-10. 
scanner. Second, as the coordinator was hired by the centre, his office was on the fourth floor. Historians from the centre consequently utilised his service much more than historians from the institute. One historian from the institute said in the interview that she preferred to scan books herself with the regular office flatbed scanner, which was quicker and right next to her office. ${ }^{357}$ Although the physical distance to the lab, located on the first floor, was similar for both the institute and centre, the physical distance to the coordinator became a significant determinant of use. The labs consequently became more aligned with the centre rather than the institute. The historians from the institute were hardly aware of what equipment was present. They maintained their view of the HiPoPhil Lab as a library, and rarely entered the Digital History Lab.

A few scholars, mainly in PhD positions, did try digital experiments within the lab, notably experiments of distant reading. Such projects required a larger number of books to be digitised, for which these scholars received training to learn how to operate the book scanner themselves. Throughout their projects, the lab coordinator assisted where needed, in cooperation with the rest of the Digital Research Infrastructure unit. Such projects were largely conducted from within the HiPoPhil Lab as this provided the book scanner and PCs with OCR software that were powerful enough for subsequent computational analyses such as topic modelling. In these projects then, the labs, especially the HiPoPhil Lab, became associated with experimentation and collaboration.

3D technology did not receive as much interest from historians as we had hoped. Two PhD candidates actively explored 3D scanning, using the available 3D scanners for objects outside of the lab. 3D scanning was thereby arguably associated with controlled settings, in creating a digital representation of phenomena outside the lab that historians could not import physically. For example, one historian scanned Roman tomb stones for close observation in her office. One significant threshold to 3D adoption was that the 3D printer required much more tacit knowledge and time investment than anticipated. The device was promised as a plug-and-play device; loading in the model and simply letting it print. Yet during the 20 hours that it took to print a model, the device demanded close attention, as small mistakes could destroy all the work that had been done. As such, despite several experiments, it did not become an infrastructural component to any historical research. Note that the most significant experiments were with $\mathrm{PhD}$ candidates. It was therefore suggested that ideally the material implications of the lab would be incorporated in hiring procedures; to attract $\mathrm{PhD}$ candidates who would 
invest significant time with the lab for their research. ${ }^{358}$ Yet during my research at the University of Luxembourg, the Digital History Lab was usually empty, in contrast with a science lab.

In conclusion, both labs ultimately became associated with infrastructural space, especially in the form of equipment and services. The HiPoPhil Lab was always meant as a tactical term, though from the start associated with infrastructural space as well to provide storage and training. It could not provide the space for training but did offer storage and equipment for digitisation as envisioned. Through this equipment for digitisation, the HiPoPhil Lab and Digital History Lab became associated with experimentation and collaboration in a few distant reading projects, at least for the scholars performing those projects. To establish these associations more firmly, efforts were eventually made to build upon these initial experiments in communications and hiring procedures.

\section{Trading Zones Emerging Across Institutional Boundaries}

During the four and a half years of my research, the University of Luxembourg significantly changed in practices related to digital history. The above history provides some insights, from my own perspective as well as from the perspectives of several interviewees, into how multiple interventions led to trading zones and boundary practices.

In line with the findings of the online questionnaire, the $\mathrm{C}^{2} \mathrm{DH}$ can be described as a collaboration consisting of mostly humanities scholars, specifically historians, that was located in multiple offices on a single floor. Participants in this trading zone had regular interactions with other disciplines. Some shared offices or collaborated with computer scientists, (software) engineers, or computational linguists. They also had regular interactions with peers from the historical discipline, among themselves and from the Institute for History, as well as peers at other universities or research institutes. The historians at the centre thus regularly performed boundary crossing, both across disciplinary boundaries within the centre, as across institutional boundaries with historians outside the centre. Furthermore, the status of centre facilitated further cross-institutional collaborations, leading to strategic partnerships with other institutes including the Center for History and New Media at George Mason University. As the centre firmly positioned itself as a place of expertise with respect to digital research and teaching,

358 Interview 8. 
it acquired the means to influence and help shape the digital strategy of the University of Luxembourg. ${ }^{359}$

Historians from the centre and the institute also performed boundary construction. This boundary construction was often not intended, and occurred through interventions by others, notably politicians and the university's rectorate. Yet historians consequently came to identify themselves with their institutional unit, sceptical of the other unit, separated on different floors in the same building.

While previous research identified group formation at different sites between people with similar backgrounds, the current study demonstrates group formation at a single site, in a single building, between people with similar backgrounds. $^{360}$ This boundary construction, however, mainly occurred on a political level, i.e. with respect to attracting new positions and funding. On a scholarly level, historians from both units agreed the split was artificial and that historians would collaborate or even act as a single group with respect to research and teaching. Insofar as there was a split in research, this was between contemporary and non-contemporary history, rather than digital and non-digital history. Although digital history was more explicit at the centre as a topic of interest, the historians at the institute conducted several projects that arguably fell within the scope of digital history.

The historians at the centre did shift practices in three notable ways. First, English became the working language, rather than French and German, both a result of and leading to more internationally diverse hiring. Second, as a centre that was supposed to have societal impact, historians became much more concerned with communication to the public than they had been at the institute. This is not to say that this did not happen at the institute, as several historians there regularly appeared on the radio or in the newspapers, but at the centre this was professionalised more broadly, including a communication office and regular public events. Third, as the centre was organised around research topics rather than the traditional chairs, intended to boost sharing of information, the historians there adopted a more corporate style with a manager per topic and regular team meetings.

Historians did not shift practices towards the few engineers or computer scientists that were present in or collaborated with the centre. Instead, the computational experts of the Digital Research Infrastructure unit arguably shaped their

359 Interview with Andreas Fickers, director of the $C^{2} \mathrm{DH}$, March 2020.

360 Armstrong and Cole, "Managing Distances and Differences in Geographically Distributed Work Groups.” 
practices to fit the conceptions of historical research. Rather than providing a generic infrastructure and shaping historians to work with it, the DRI emphasised the need to provide diverse and loosely coupled infrastructural components to fit the heterogeneous demands of historians. As such, if I were to describe the centre limited to this duality, I would conclude that the centre constituted a connectedasymmetric-homogeneous (subversive) trading zone, with historians in a powerful role and computational experts learning and appropriating historical practices and values through continued interactions. The shifts in practices that historians did exemplify aligned not to computational experts, but to the political goal of the centre. This power relation was not always obvious, and who stated goals not always clear. In that sense, the centre constituted a disconnected-asymmetrichomogeneous (subversive) trading zone, where the historians changed practices through a unidirectional power relation that was not always explicit and involved little engagement with those who ultimately decided the shape of the centre.

In contrast, the presence of a Digital History Lab did not suddenly shape the practices of historians. Some historians adopted technologies and tools that were offered in the labs, yet the majority of historians initially did not engage with the lab apart from occasionally requesting a digital copy of a book. While digital humanities labs have been argued to act as epistemic infrastructures shaping how scholars ask questions, my case study shows this is not by necessity but rather by individual interests. ${ }^{361}$ Rather than the labs naturally acquiring associations of experimentation and collaboration, this required efforts in communication and hiring procedures to attract historians to engage with the labs. The presence of labs extended the possibilities of research, yet did not limit possibilities by excluding practices that may not make optimal use of the lab space. The presence of certain tools and technologies did not limit what could be done with the lab space, contrary to the aforementioned material implications of labs, as historians continuously negotiated how the labs would fit their purposes. ${ }^{362}$ The labs thereby did not provide much opportunity for cross-disciplinary boundary crossing, nor did the labs give rise to boundary construction between disciplinary or institutional communities. In conclusion, I argue that the labs constituted disconnected-symmetricheterogeneous (boundary object) trading zones, constantly shifting associations to what it means for a space to be a lab.

361 C.f. James W. Malazita, Ezra J. Teboul and Hined Rafeh, "Digital Humanities as Epistemic Cultures: How DH Labs Make Knowledge, Objects, and Subjects,” Digital Humanities Quarterly 14 , no. 3 (2020).

362 C.f. Foka et al., "Beyond Humanities qua Digital.” 
In conclusion, how disciplinary and institutional boundaries were crossed or constructed depended on who was pushing against existing boundaries and what power they had to do so. While the dimension of engagement shaped interactions between people, this dimension itself was shaped by those who were in the position to decide where scholars would be affiliated or physically placed. The next chapter, therefore, further explores the dimension of power relations. 